\title{
The Correlation between Parental Attitude and Susceptibility to Drug Addiction among Students
}

\author{
Elena A. Cheverikina ${ }^{1}$, Nataliya A. Kora ${ }^{2}$, Juliya V. Badalyan ${ }^{2}$, Tatyana V. Klimova ${ }^{2}$, Tatyana S. Yeremeyeva ${ }^{2}$, \\ Ekaterina V. Mokeyeva ${ }^{3}$ \& Alfiya R. Masalimova ${ }^{3}$ \\ ${ }^{1}$ The Institute of Pedagogic and Psychology of Professional Education of Russian Academy of Education, Kazan, \\ Tatarstan, Russia \\ ${ }^{2}$ Amur State University, Amur Region, Russia \\ ${ }^{3}$ Kazan Federal University, Tatarstan, Kazan, Russia
}

Correspondence: Elena A. Cheverikina, The Institute of Pedagogic and Psychology of Professional Education of Russian Academy of Education, Kazan, 420039, Russia. E-mail: cheverikina@mail.ru

Received: October 24, 2014 Accepted: December 3, 2014 Online Published: December 18, 2014

doi:10.5539/res.v7n1p5

URL: http://dx.doi.org/10.5539/res.v7n1p5

\begin{abstract}
The susceptibility to drug addiction affects the formation of the students personality. One of the reasons of its appearance is the socialization defects within the family, regrettable attitude of parents to children. The purpose of this article is to identify and investigate the particularities of the parental attitude to the students of the secondary vocational and higher education institutions who have different levels of susceptibility to drug addiction. To analyze the parental attitude two criteria are used in the research: the degree of emotional bond, parents' attachment to the child (love, acceptance, warmth or emotional rejection and coldness) and the degree of control over his behavior (high-with lots of restrictions and prohibitions; low-the minimum prohibitive tones). They represent three main factors: positive interest vs. hostility, directivity vs. autonomy and inconsistency as a sharp transition from one extreme to another. The research shows that the formation of susceptibility to addiction among the students of the secondary vocational schools is influenced by the particular attitudes of both parents, while university students are mostly affected by their mothers' attitude. It is found that the particularities of the child-parent relationships in forming susceptibility to addiction affect more the students of the secondary vocational schools than the higher education students. The research data allow to improve the psycho-pedagogical programs aimed at reducing drug addiction susceptibility among students.
\end{abstract}

Keywords: students, susceptibility to drug addiction, child-parent relationships, mother's attitude, parental attitude

\section{Introduction}

The research is important today because of the widespread tendency to addictive behaviour among youth in general and among students in particular.

Examining the students socialization defects that have a negative impact and predisposing susceptibility to psychoactive substances, we found that the loss of positive family stimulus is one of the most important factors influencing the drift to alcohol and drug addictions (Cheverikina, 2012).

The "parent-child" relationships are essential for understanding the direction of the future development of the child. The child-parent relationships are selective emotional and evaluative psychological attachment of the child to each parent in terms of emotions, actions, reactions associated with the age-related psychological characteristics of children, cultural patterns of behaviour and personal life story which determines the perception of the parents by the child and the way to communicate with them (Smolyarchuk, 2009)

In psychological and educational studies to determine and analyze the parental attitude the two criteria are used: the degree of emotional bond, parents warmth towards the child (love, acceptance, warmth or emotional rejection and coldness) and the degree of control over his behavior (high-with lots of restrictions and prohibitions; low-the minimum prohibitive tones). (Zmanovskaya, 2006; Masalimova 2014). At the same time, many empirical studies which were carried out in our country and abroad earlier state that the attitude, behaviour and educational tactics of the parents as their children in adolescence and youth age conceive represent three 
main factors: positive interest-hostility, directivity-autonomy and inconsistency as a sharp transition from one extreme to another (Wasserman, Gorkovskaya, \& Romitsyna, 2004).

The study of the parental attitude to the students who are susceptible to addiction will reveal their characteristics that can become the target for further psychological correction work to reduce the incidence of drug addiction among students.

The object of the research is the students of higher and secondary professional educational institutions with different levels of susceptibility to addiction.

The subject of the research: the peculiarities of child-parent relationships that affect susceptibility to drug addiction.

Research objectives: to make a theoretical analysis of the scientific literature of the problem of child-parent relationships with the students susceptible to drug addiction; to make an empirical study using the relevant tools among higher and secondary vocational education students, susceptible to psychoactive substances to reveal the peculiarities of the child-parent relationship that affect formation of susceptibility to alcohol and drug addictions.

Research hypothesis: there are distinctions in influence of features of the relation from parents on formation of tendency to drug addiction at students of an average and higher education.

\section{Materials and Methods}

The data for the empirical study was provided by 186 students of the Kazan medical College, Kazan), 21 students of Kazan (Volga) Federal University, Kazan) and 135 students of Amur state University, Blagoveshchensk who participated in the experiment.

The completed study was based on the following techniques: 1. ADOR, adaptation by Wasserman L. I., Gorkovskaya I. A., Romitsyna E. E. which is aimed at the study of the parents attitudes, behaviour and methods of education as seen by their children in their teens (Wasserman, Gorkovskaya, \& Romitsyna, 2004). 2. The questionnaire "Susceptibility to addiction" (Cheverikina \& Gryaznov, 2012) to identify the students at risk of substance abuse.

\section{Results}

The analysis of the data according to the ADOR methodology has shown that the students with a high susceptibility to drug addiction have higher rates at the scales of directivity, hostility and inconsistency, which suggests that the parental hostile attitude to them is overwhelming. With this type of child-parent relationship the educational practice is considered to be inconsistent, tough and rigid. Apparently, we observe excessive care and its rejection by the student. In most cases, it causes confrontation with their parents and behavioral disorders, including a drift to the psychoactive substance abuse.

The students with a low and high susceptibility to addiction have revealed the significant differences in the average figures on the scales of hostility, inconsistency and proximity from both father and mother (table 1).

Table 1. The significant differences of the average figures according to the ADOR scale with the students of low and high susceptibility to drug addiction

\begin{tabular}{lllll}
\hline & \multicolumn{3}{c}{ mother } & \multicolumn{3}{c}{ father } \\
\cline { 2 - 5 } & T-index & $\mathrm{p}$ & T-index & $\mathrm{p}$ \\
\hline Positive interest & 1.18 & 0.24 & 1.06 & 0.29 \\
Directivity & -0.50 & 0.61 & -0.90 & 0.37 \\
Hostility & $-2.76^{*}$ & 0.01 & $-3.68^{*}$ & 0.00 \\
Autonomy & -0.71 & 0.47 & 0.26 & 0.79 \\
Inconsistency & $-2.53^{*}$ & 0.01 & $-2.06^{*}$ & 0.04 \\
Attachment & $2.10^{*}$ & 0.04 & $2.97^{*}$ & 0.00 \\
Criticism & -0.31 & 0.76 & -0.84 & 0.40 \\
\hline
\end{tabular}

* - differences in the average are valid at the level of $p \leq 0.05$ 
High mother hostility which is marked by the students with a high susceptibility to alcoholism is expressed in mother's distance from the family members, suspicion towards them, as well as feeling superior to them. Father hostility is expressed in emotional coldness and rejection of the child which leads to his increased nervousness, tension and emotional imbalances.

Inconsistency on the mother's side showing in a sharp change of styles and upbringing techniques, a jump from strict to liberal education, from psychological acceptance to emotional rejection regardless of the child's behavior leads to emerging susceptibility to drug addiction Inconsistency on father's side is also expressed in his absolute unpredictability.

The relationships between parents and the students with a high susceptibility to alcoholism is mainly characterized by cold attitude which can be both low and high.

The correlation analysis of the received data with the Pearson correlation coefficient has shown that susceptibility to drug addiction is affected by hostility and maternal lack of positive interest and attachment (table 2).

Table 2. The correlation between susceptibility to drug addiction and maternal upbringing techniques

\begin{tabular}{ll}
\hline & $\begin{array}{l}\text { Susceptibility to } \\
\text { addiction }\end{array}$ \\
\hline Positive interest & $-0.244^{* *}$ \\
Directivity & -0.51 \\
Hostility & $0.267^{* *}$ \\
Autonomy & -0.018 \\
Inconsistency & 0.155 \\
Attachment & $-0.317^{* *}$ \\
Criticism & -0.27 \\
\hline
\end{tabular}

** - correlations are valid at the level of $\mathrm{p} \leq 0.01$

As for father's influence on student's susceptibility to addiction it is mostly concerns hostility, inconsistency and lack of closeness (table 3).

Table 3. The correlation between fathers upbringing behavior and the inclination to drug abuse

\begin{tabular}{ll}
\hline & $\begin{array}{l}\text { Susceptibility to } \\
\text { addiction }\end{array}$ \\
\hline Positive interest & -0.087 \\
Directivity & 0.072 \\
Hostility & $0.365^{* *}$ \\
Autonomy & 0.094 \\
Inconsistency & $0.248^{* *}$ \\
Attachment & $-0.280^{* *}$ \\
Criticism & 0.003 \\
\hline
\end{tabular}

** - correlations are valid at the level of $\mathrm{p} \leq 0.01$

Thus, it is found that the formation of susceptibility to addiction is influenced by hostility, inconsistency and lack of attachment from both mother and father.

The higher education students with low and high susceptibility to addiction show significant differences in the average at scales of Hostility, Inconsistency, Attachment and Criticism. When analyzing the reliable differences 
in the average the attitude of the father also has not been identified (tables 4 and 5).

Table 4. Significance of differences of the ADOR average rates of the higher education students with different levels of susceptibility to drug addiction (maternal attitude)

\begin{tabular}{llll}
\hline & \multicolumn{3}{c}{ Susceptibility to drug addiction } \\
\cline { 2 - 4 } & low/high & low/average & average/high \\
\hline Positive interest & 0.558 & -0.290 & 0.426 \\
Directivity & -1.745 & 0.476 & 0.721 \\
Hostility & $-3.189^{*}$ & 0.570 & 0.119 \\
Autonomy & 1.781 & -0.064 & -0.269 \\
Inconsistency & $-4.129^{*}$ & -0.369 & 0.791 \\
Attachment & $2.264^{*}$ & -0.492 & 0.184 \\
Criticism & $-2.240^{*}$ & 0.356 & 0.663 \\
\hline
\end{tabular}

(Student's t-test)

* - differences in the average are valid at the level of $\mathrm{p} \leq 0.05$

Table 5. Significance of differences of the ADOR average rates of the higher education students with different levels of susceptibility to drug addiction (paternal attitude)

\begin{tabular}{llll}
\hline & \multicolumn{3}{c}{ Susceptibility to drug addiction } \\
\cline { 2 - 4 } & low/high & low/average & average/high \\
\hline Positive interest & 1.045 & 0.493 & 0.592 \\
Directivity & -0.080 & -0.371 & 0.196 \\
Hostility & -1.719 & -1.065 & -0.861 \\
Autonomy & 1.914 & 0.656 & 1.314 \\
Inconsistency & -0.851 & -0.437 & -0.499 \\
Attachment & 1.886 & 0.902 & 0.957 \\
Criticism & -1.272 & -0.636 & -0.882 \\
\hline
\end{tabular}

(Student's t-test)

* - differences in the average are valid at the level of $\mathrm{p} \leq 0.05$

Thus, the formation of susceptibility to drug addiction among higher education students is greatly influenced by the mother's distance from the family, aloofness from its members, as well as the lack of warmth and attachment. Paternal education and attitude are not so significant. But drug addiction among students of higher education may also appear as a result of unexpected change of mothers educational styles and techniques as well as strongly critical attitude on her part.

The data concerning the students of the secondary vocational schools with low and high susceptibility to drug addiction have shown significant differences in the average rates at almost the same scales as those of alcohol addiction, except for the scale of paternal Positive interest (tables 6,7). 
Table 6. Significance of differences of the ADOR average rates of the secondary vocational education students with different levels of susceptibility to drug addiction (maternal attitude)

\begin{tabular}{llll}
\hline & \multicolumn{3}{c}{ Susceptibility to drug addiction } \\
\cline { 2 - 4 } & low/high & low/average & average/high \\
\hline Positive Interest & $2.529^{*}$ & 0.426 & 1.546 \\
Directivity & -0.220 & 0.721 & -0.817 \\
Hostility & $-2.769^{*}$ & 0.119 & $-2.070^{*}$ \\
Autonomy & -1.538 & -0.269 & -0.930 \\
Inconsistency & $-2.564^{*}$ & 0.791 & $-2.457^{*}$ \\
Attachment & $3.358^{*}$ & 0.184 & $2.208^{*}$ \\
Criticism & 0.893 & 0.663 & -0.001 \\
\hline
\end{tabular}

(Student's t-test)

* - differences in the average are valid at the level of $\mathrm{p} \leq 0.05$

Table 7. Significance of differences of the ADOR average rates of the secondary vocational education students with different levels of susceptibility to drug addiction (parental attitude)

\begin{tabular}{llll}
\hline & \multicolumn{2}{c}{ Susceptibility to drug addiction } \\
\cline { 2 - 4 } & low/high & low/average & average/high \\
\hline Positive interest & 1.528 & 0.669 & 0.602 \\
Directivity & -1.064 & -0.452 & -0.425 \\
Hostility & $-4.406^{*}$ & -1.385 & $-2.224^{*}$ \\
Autonomy & -1.018 & 0.486 & -1.466 \\
Inconsistency & $-3.798^{*}$ & -1.622 & -1.615 \\
Attachment & $3.626^{*}$ & 1.218 & 1.736 \\
Criticism & -0.192 & -0.683 & 0.560 \\
\hline
\end{tabular}

(Student's t-test)

* - differences in the average are valid at the level of $p \leq 0.05$

\section{Discussions}

The foreign scientists are studying the problem of Internet addiction and the problem of youth safety in cyberspace, the problem of overweight and food addiction (Shahsavar et al., 2013), the dependence of drug use and HIV (Bayatmakoo, Bayatmakoo, Saleh, \& Mashrabi, 2012), neuropsychological consequences of drug addiction (Amirfakhraei \& Alinaghizadeh, 2012).

In most cases, Russian scientists studied the effect of parental attitude on socialization and adaptation, as well as involvement of the preschool and school-age children, adolescents in drug abuse. The research was made on such problems as personal characteristics of the adolescents with addictive behavior in the families of violated paternal function (Ustseva, 2011), psychological factors of forming resistance to gambling addiction in adolescence (Pereverzeva, 2009), the violation of the relationships between mother and child as a risk factor for adolescence drug addiction (Hristoforova, 2004). Structural and dynamic approach to the study of the child-parent relationship influence in the formation of deviant behavior was developed (Zmanovskaya, 2006). There were studies of the psychological correction methods intended for destructive child-parent relationships (Zhdakaeva, 2012) and psychological correction of the child-parent relationships with socially and educationally neglected teenagers (Kurmanova, 2003), psycho-pedagogical conditions for developing constructive parental attitudes towards young drug addicts (Korovina, 2009).

In national science there was a research made on the discrepancy between the existing societal rejection of substance abuse by the students, awareness of the university and public administration of the general situation, 
the young people awareness of the dangers of psychoactive substance abuse, the efforts that had been made in this area by the State and public organizations and continuing growth of drug addiction among students (Tsvetkova, 2011), the social-psychological characteristics of the students susceptible to psychoactive substances (Cheverikina, 2012).

The analysis of the scientific research has shown that the available scientific data on the parental attitudes to the university students and secondary vocational education students who are susceptible to addiction, are insufficient for the future development of the effective programs to reduce susceptibility to drug addiction among students in order to educate healthy, erudite, educated and creative specialists within the socialization in the family, as well as in higher and secondary vocational education system.

\section{Conclusion}

The study allows to make a conclusion that to minimize the risk of susceptibility to drug addiction among students the psychological service of universities and other educational organizations, educators, and tutors should focus on improving trust and acceptance within their families towards their adult children especially on mother's side, provide confidence and absence of violence, authoritarianism on father's side, i.e. eliminate all kinds of pressure from education. In order to prevent susceptibility to drug addiction it is important to pay attention to consistent, smooth and harmonious education in the family, without unexpected fluctuations from austerity to liberalism, from restrictions to excessive permissiveness.

The socio-psychological work with the families of secondary professional educational students who are susceptible to drug addiction demands a work with both parents, while working with the families of university students with a high susceptibility to addiction it is important to focus on their mothers.

Prospective and requiring further research are the issues concerning identification of the psychological, social-psychological and social factors that influence the destructive parental attitudes that develop predisposition to addiction among their children.

\section{References}

Azita, A., \& Afsaneh, A. (2012). Epidemiology of mental disorders among adolescents in the city of Bandar Abbas, Iran, in 2012. Life Science Journal, 9(3), 976-980.

Cheverikina, E. A. (2012). Defects of socialization as a factor of formation of tendency to addiktivny behavior at students. Bulletin of the Kazan state power university, 4(15), 110-118.

Cheverikina, E. A. (2012). Social and psychological features of students of the higher education institutions inclined to dependence on psychoactive agents. Kazan pedagogical magazine, 6, 110-118.

Cheverikina, E. A., \& Grjaznov, A. N. (2012). Technique of diagnostics of tendency to addiktion at students (pp. 316-319). In the Proceedings of the 2012 international scientific and practical conference "Professional features of social work with children and youth: Questions of the theory and innovative practice in training of students for work in this sphere", Kazan.

Farhad, S., Koroush, G., Mehrzad, J., Bahram, N., \& Shahab, F. (2013). Opium addiction decreases T3 uptake amount. Life Science Journal, 10(5s), 608-610.

Hristoforova, M. I. (2004). Violation of relationship between mother and the child as risk factor of a drug addiction of teenagers (p. 254) (M. S. thesis, St. Petersburg).

Korovina, O. E. (2009). Psychology and pedagogical conditions of formation of the constructive parental relation to drug-addicted young men (p. 201) (M. S. thesis, Samara).

Kurmanova, N. S. (2003). Psychological correction of child-parent relationships and social pedagogically neglected adolescents (p. 233) (MS thesis, Kazan).

Masalimova, A. R. (2014). Mentoring perfection in modern enterprises conditions: Practical re-commendations. American Journal of Applied Sciences, 1152-1156. http://dx.doi.org/10.3844/ajassp.2014.1152.1156

Pereverzeva, A. A. (2009). Psychological factors of formation of resistance to a game addiction at teenage age (p. 214) (M. S. thesis, Tambov).

Smolyarchuk, I. V. (2009). Parent-child relationship and their impact on the development of the child's personality. Tambov Univ TSU.

Tsvetkova, L. A. (2011). Social psychology of a narkotizm in the student's environment (p. 469) (M. S. thesis, St. Petersburg). 
Ustseva, M. N. (2011). Personal features of teenagers with addiktivny behavior in families with violation of fatherly function (p. 187). (M. S. thesis, Moscow).

Wasserman, L. I., Gorkovskaya, I. A., \& Romitsyna, E. E. (2004). Parents in the eyes of teenager: Psychological diagnostics in medical and pedagogical practice (p. 256). St. Petersburg.

Zhdakaeva, E. I. (2012). Psychological correction means destructive parent-child relationship (p. 216). (MS thesis, Omsk).

Zhinous, B., Roshanak, B., Parviz, S., \& Omid, M. (2012). Study on infectious causes of hospitalization in intravenous drug users. Life Science Journal, 9(4), 602-606.

Zmanovskaya, E. V. (2006). Psychology of deviant behavior: Structural and dynamic approach (p. 450). (M. S. thesis, St. Petersburg).

\section{Copyrights}

Copyright for this article is retained by the author(s), with first publication rights granted to the journal.

This is an open-access article distributed under the terms and conditions of the Creative Commons Attribution license (http://creativecommons.org/licenses/by/3.0/). 